\title{
Ectopic Cushing's syndrome due to retroperitoneal ACTH-producing paragangliomas
}

\author{
Fan Chen, MD, ;, ${ }^{*}$ Xiangyu Wang, MD, ${ }^{3 *}$ Yang Wang, MD; ${ }^{4 *}$ Hui Meng, MD; ${ }^{; 1}$ Xinguo Hou, MD, ${ }^{5}$ Yaofeng Zhu, \\ MD;' Wei Gao, MD,6,7 Xuewen Jiang, MD;1 Shouzhen Chen, MD;' Zhaocun Zhang, MD;'1 Zhichuan Zou, MD; \\ Tianyi He, MD; ${ }^{5}$ Yue Yang, MD; ${ }^{1}$ Kejia Zhu, MD;1 Yong Wang, MD; '1 Yaxiao Liu, MD;1 Jianfeng Cui, MD;1 \\ Benkang Shi, MD;' Gang Yin, MD'
}

'Department of Urology, Qilu Hospital, Shandong University, Jinan, Shandong, China; ${ }^{2}$ College of Medicine, University of Kentucky, Lexington, KY, United States; ${ }^{3}$ Department of Urology, The People's Hospital of Liaocheng, Liaocheng, Shandong, China; ${ }^{4}$ Department of Urology, Affiliated Hospital of Chengdu University, Chengdu, Sichuan, China; ${ }^{5}$ Department of Endocrinology, Qilu Hospital, Shandong University, Jinan, Shandong, China; ${ }^{6}$ Department of Pathology, Qilu Hospital, Shandong University, Jinan, Shandong, China; ' Department of Pathology, Jinan Central Hospital, Shandong University, Jinan, Shandong, China

*Equal contributors

Cite as: Can Urol Assoc J 2016;10(9-10):E320-3. http://dx.doi.org/10.5489/cuai.3153 Published online September 13, 2016

\section{Abstract}

Extra-adrenal pheochromocytomas, or paragangliomas, are rare tumours that derive from extra-adrenal chromaffin cells. Cushing's syndrome (CS) caused by paragangliomas is extremely rare. We report a 53-year-old man with hypertension, diabetes, and symptoms of hypokalemia. Computer tomography $(\mathrm{CT})$ revealed two retroperitoneal masses and bilateral adrenal hyperplasia. Together with the laboratory examinations, ectopic CS caused by multiple paragangliomas was highly suspected. The patient underwent resections of retroperitoneal tumours, left kidney, and left adrenal; postoperative histopathology confirmed two paragangliomas that were both positively stained for adrenocorticotropic hormone (ACTH). He got clinical and biochemical recoveries without any recurrent evidence at the nine-month followup.

\section{Introduction}

Cushing's syndrome (CS) is a very rare disease with an incidence of around five per million. CS can be divided into adrenocorticotropin hormone (ACTH)-dependent and ACTH-independent disease. ${ }^{1}$ Of the ACTH-dependent cases, 80-90\% of cases are due to Cushing's disease, a pituitary adenoma; the others are the ectopic ACTH syndrome (EAS). ${ }^{2}$ Paraganglioma is a kind of tumour that arises from extraadrenal paraganglia and consists of specialized neural crestderived cells. ${ }^{3}$ EAS caused by paraganglioma is extremely uncommon, especially those caused by abdominal paraganglioma. Here, we present a case of multiple retroperitoneal ACTH-secreting paragangliomas — the first one to be reported.

\section{Case report}

A 53-year-old man was admitted to the hospital due to a two-month history of polyphagia, polyuria, and polydipsia, and a 10-day history of severe limb numbness, fatigue, generalized weakness, dizziness, and bilateral blurry vision. He suffered from diabetes mellitus and hypertension (180/116 $\mathrm{mmHg}$ ) for nine months and experienced a $10 \mathrm{~kg}$ weight loss. He denied being prescribed any drugs recently, including steroids. During his hospitalization, mental disorders, such as dysphoria, mental excitement, and hallucination occurred several times.

Physical examination manifested typical CS features, including buffalo hump, moon face, and violaceous striae in his abdomen and thighs. Mild edema could be found in his lower extremities and red patches were scattered on his whole body, especially the chest.

No apparent abnormality was found on pituitary contrastenhanced computed tomography (CT) scan. A severe pulmonary infection of Streptococcus pneumoniae was identified by CT and sputum culture. Abdominal contrast-enhanced CT scan revealed a left retroperitoneal mass measuring about $4.8 \mathrm{~cm}$ in diameter; extra-adrenal paraganglioma was highly suspected, with a minor lymph node-like mass adjacent to it and bilateral adrenal hyperplasia (Fig. 1). The patient's serum potassium was low $(2.0 \mathrm{mmol} / \mathrm{L})$ and routine blood test suggested ongoing infection. He also had hyperglycemia $(11.5 \mathrm{mmol} / \mathrm{L})$. Furthermore, the multiple determinations of blood cortisol and ACTH showed they were in high levels and lost their intrinsic diurnal variations. Cortisol failed to be suppressed by large-dose dexamethasone. However, 24-hour urinary catecholamine and blood catecholamine were within normal range. Based upon these findings, the diagnosis of EAS caused by ACTH-producing retroperitoneal 
paragangliomas was suspected.

The patient was given phenoxybenzamine hydrochloride for two weeks before surgery to control his high, erratic blood pressure. Then, he underwent resections of retroperitoneal tumours, left kidney, and left adrenal, for which it was difficult to separate the tumours from the left kidney and adrenal gland safely. Postoperative pathological examination was compatible with extra-adrenal paragangliomas, which were both immunostained with ACTH, chromogranin A, Syn, and S100 positively (Fig. 2). The histopathology of the removed adrenal gland showed a normal gland tissue.

After the surgery, the patient's blood pressure, serum glucose, and potassium normalized gradually, with no symptomatic medication. Postoperative levels of plasma ACTH and cortisol switched back to normal in three days. At the nine-month followup, the patient showed complete clinical recovery without any evidence of recurrence.

\section{Discussion}

Paragangliomas are rare neuroendocrine tumours that arise from extra-adrenal paraganglia and consist of specialized catecholamine-secreting chromaffin cells. Hormonal and immunohistological studies suggested that our patient suffered from functional paragangliomas with ACTH secretion. EAS cases due to paraganglioma have been reported in only 10 patients (Table 1). ${ }^{4-13}$ The tumour was located in the mediastinum in four of them, in paranasal sinus in three, and in the retroperitoneum in three patients. Only one patient had malignant tumours located throughout the thorax and abdomen. Our patient is the only one reported to have multifocal ACTH-producing paragangliomas that were benign. The ages of all the patients ranged from 12-70 years and eight of them were female. Ten patients had hypertention

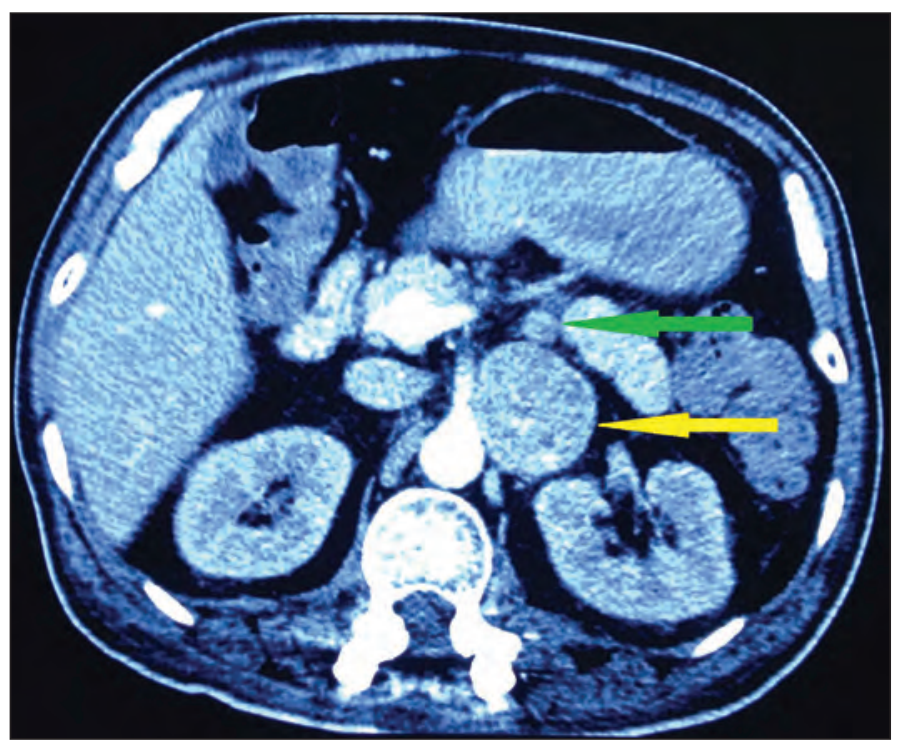

Fig. 1. Contrast-enhanced computed tomography of abdomen showed a larger retroperitoneal mass (yellow arrow), measuring about $4.8 \mathrm{~cm}$ in diameter, a minor retroperitoneal mass (green arrow) and bilateral adrenal hyperplasia.

and nine presented hyperglycemia. Hypokalemia was seen in seven patients. Excess excretion of catecholamine was reported in only three patients, conforming to the previous study that about $20 \%$ of the paragangliomas had been documented with catecholamine hypersecretion. ${ }^{14}$

Ectopic ACTH-producing tumours produce ACTH, but they usually can not reduce the secretion of ACTH via classic negative feedback loops successfully. Consequently, the glucocorticoid excess in EAS cases is often more severe than Cushing's disease. ${ }^{9}$ The excessive cortisol secretions may lead to hypertension, hypokalemia, hyperglycemia, and suppression of the immune system. Infections are more apt to occur and difficult to control before the tumour resection.

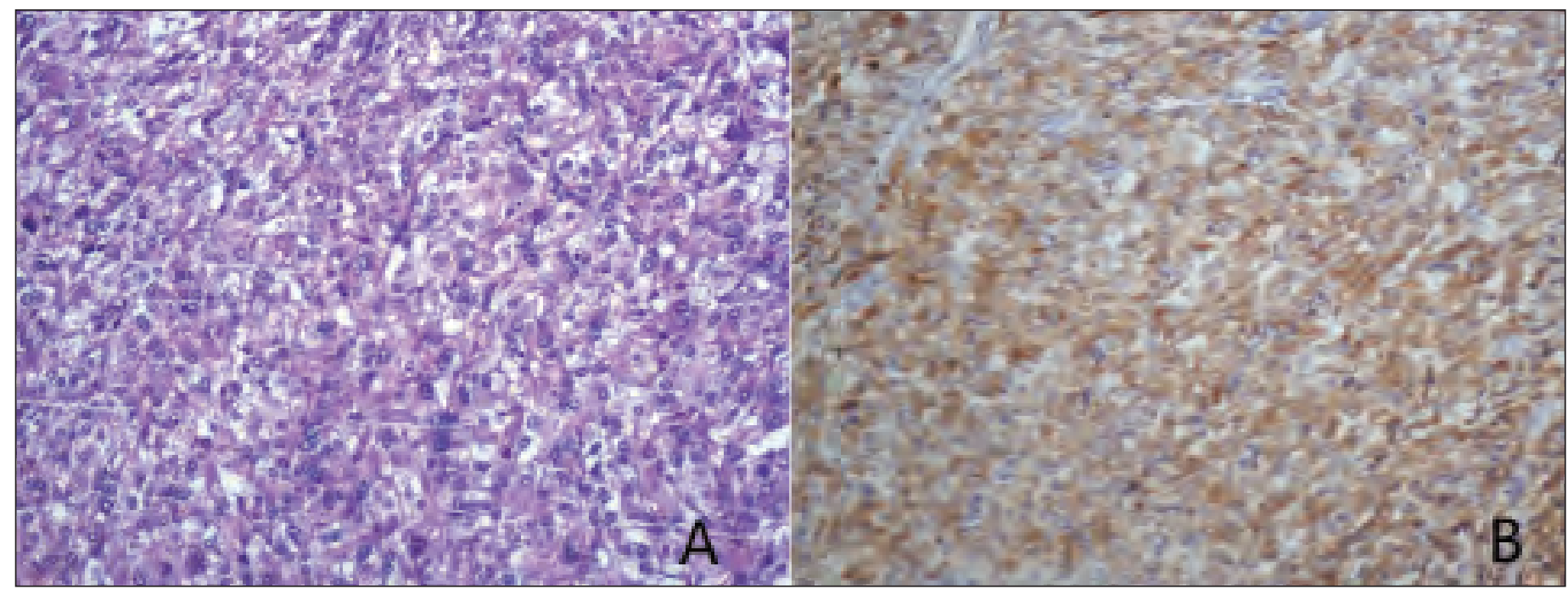

Fig. 2. Pathologic finding of the resected larger mass. (A) Hematoxylin-eosin staining; (B) Positively staining for adrenocorticotropin (ACTH). 


\begin{tabular}{|c|c|c|c|c|c|c|c|c|c|}
\hline Authors & $\begin{array}{l}\text { Age/ } \\
\text { gender }\end{array}$ & $\begin{array}{l}\text { Cortisol } \\
\text { (ug/dl) }\end{array}$ & Hypertension & Hyperglycemia & $\begin{array}{l}\text { Potassium } \\
\text { (mmol/L) }\end{array}$ & $\begin{array}{c}\text { ACTH } \\
\text { (pg/ml) }\end{array}$ & $\begin{array}{c}\text { Catecholamine } \\
\text { excess }\end{array}$ & Location & Outcome \\
\hline $\begin{array}{l}\text { Kitahara et } \\
\text { al, } 1993^{4}\end{array}$ & $12 / \mathrm{F}$ & 107.1 & + & + & 4.2 & 13.6 & + & $\begin{array}{l}\text { Lung; } \\
\text { retroperitoneum }\end{array}$ & $\begin{array}{l}\text { Died; malignant } \\
\text { paraganglioma }\end{array}$ \\
\hline $\begin{array}{l}\text { Park et al, } \\
2000^{5}\end{array}$ & $51 / \mathrm{F}$ & 59 & + & + & 2.5 & 278 & - & $\begin{array}{c}\text { Anterior } \\
\text { mediastinum }\end{array}$ & $\begin{array}{c}\text { Died of } \\
\text { mediastinitis } \\
\text { with combined } \\
\text { pneumonia } \\
22 \text { days after } \\
\text { operation }\end{array}$ \\
\hline $\begin{array}{l}\text { Lieberum } \\
\text { et al, } 2003^{6}\end{array}$ & $64 / \mathrm{M}$ & High & + & + & Low, ND & 95.6 & - & Paranasal sinus & Recovery \\
\hline $\begin{array}{l}\text { Dahir et al, } \\
2004^{7}\end{array}$ & $39 / F$ & 30.6 & + & ND & ND & 73.0 & - & Mediastinum & Recovery \\
\hline $\begin{array}{l}\text { Otsuka et } \\
\text { al, } 2005^{8}\end{array}$ & $55 / F$ & 76.5 & + & + & 1.3 & 318.4 & + & Retroperitoneum & Recovery \\
\hline $\begin{array}{l}\text { Willenberg } \\
\text { et al, } 2006^{9}\end{array}$ & $61 / F$ & 176.0 & + & + & 3.1 & 1078 & + & Retroperitoneum & $\begin{array}{c}\text { Died of } \\
\text { pulmonary } \\
\text { bleeding } 6 \\
\text { months after } \\
\text { operation }\end{array}$ \\
\hline $\begin{array}{l}\text { Palau et al, } \\
2006^{10}\end{array}$ & $55 / \mathrm{M}$ & $\begin{array}{l}\text { High, } \\
\text { ND }\end{array}$ & ND & ND & ND & $\begin{array}{l}\text { High, } \\
\text { ND }\end{array}$ & ND & Mediastinum & Recovery \\
\hline $\begin{array}{l}\text { Fohr et al, } \\
2011^{11}\end{array}$ & 23/M & 38 & + & + & ND & 287 & ND & $\begin{array}{c}\text { Anterior } \\
\text { mediastinum }\end{array}$ & Recovery \\
\hline $\begin{array}{l}\text { Thomas et } \\
\text { al, 2013 }\end{array}$ & $70 / F$ & 74.4 & + & + & 1.7 & 273.0 & - & $\begin{array}{l}\text { Left paranasal } \\
\text { sinus }\end{array}$ & Recovery \\
\hline $\begin{array}{l}\text { Serra et al, } \\
2013^{13}\end{array}$ & $68 / F$ & 98.7 & + & + & 1.9 & 317.0 & ND & $\begin{array}{l}\text { right nasal } \\
\text { sinuses }\end{array}$ & Recovery \\
\hline $\begin{array}{l}\text { Present } \\
\text { case }\end{array}$ & $53 / F$ & 89.6 & + & + & 2.63 & 432.4 & - & Retroperitoneum & Recovery \\
\hline
\end{tabular}

In the literature, five of 11 patients had infections and one patient died of mediastinitis and pneumonia 22 days after the surgery. In our case, the patient had refractory pneumonia, which led to respiratory failure. His pulmonary infection didn't get better until the resection operation.

CS can show metabolic syndrome manifestations, such as obesity, facial plethora, decreased libido, thin skin, menstrual irregularity, hirsutism, and hypertension. Biochemical diagnostic examinations - including 24-hour urinary free cortisol, low-dose dexamethasone suppression test, and assessment of midnight plasma cortisol or late-night salivary cortisol - should be done when there is clinical suspicion. Once a diagnosis of CS is established, the first step is to measure the concentration of ACTH in plasma, which is almost greater than 3.3pmol/L in ACTH-dependent diseases. The high-dose dexamethasone suppression test and bilateral inferior petrosal sinus sampling can also help the etiologic diagnosis. ${ }^{2}$

Seeking the source of ACTH in CS can prove extremely challenging. Axial thin-section multislice CT of thorax and abdomen, MRI, or a combination of both procedures has the highest detection rate for EAS. ${ }^{2}$ Positron emission tomography (PET) CT using somatostatin analogue, ${ }^{68} \mathrm{Ga}$-DOTA-
TOC, is also effective in identifying neuroendocrine tumours. ${ }^{15}$ If traditional images make it difficult to detect catecholamine-secreting tumours, scintigraphic localization with ${ }^{123}$-metaiodobenzylguanidine is indicated. ${ }^{16}$

Surgical resection is the preferred and definitive treatment for ACTH-producing paragangliomas. Nine of the 11 patients recovered after tumour resection. To minimize the surgical complications and prevent intraoperative hypertensive crises, controls of hypercortisolemia and combination use of $\alpha$ - and $\beta$-adrenergic blockades are always required preoperatively. ${ }^{16,17}$

\section{Conclusion}

Ectopic ACTH syndrome caused by paraganglioma is remarkably uncommon. Here, we present a case that illustrates that diagnosis, localization, and treatment are indeed a huge challenge.

Competing interests: The authors report no competing personal or financial interests.

This paper has been peer-reviewed. 


\section{References}

1. Plotz CM, Knowlton Al, Ragan C. The natural history of Cushing's syndrome. Am J Med 1952;13:597-614. http://dx.doi.org/10.1016/0002-9343(52)90027-2

2. Newell-Price J, Bertagna X, Grossman AB, et al. Cushing's syndrome. Lancet 2006;367:1605-17. http://dx.doi.org/10.1016/S0140-6736(06)68699-6

3. DeLellis RA. Pathology and Genetics of Tumours of Endocrine Organs, World Health Organization Classification of Tumours. Lyon: IARC Press, 2004:320.

4. Kitahara M, Mori T, Seki H, et al. Malignant paraganglioma presenting as Cushing syndrome with viritism in childhood. Production of cortisol, androgens, and adrenocorticotrophic hormone by the tumour. Cancer 1993;72:3340-5. http://dx.doi.org/10.1002/1097-0142(19931201)72:11<3340::AlDCNCR2820721133>3.0.C0;2-2

5. Park HK, Park CM, Ko KH, et al. A case of Cushing's syndrome in ACTH-secreting mediastinal paraganglioma. Korean I Intern Med 2000;15:142-6. http://dx.doi.org/10.3904/kjim.2000.15.2.142

6. Lieberum B, Jaspers C, Munzenmaier R. ACTH-producing paraganglioma of the paranasal sinuses. HNO 2003;51:328-31. http://dx.doi.org/10.1007/s00106-002-0695-8

7. Dahir KM, Gonzalez A, Revelo MP, et al. Ectopic adrenocorticotropic hormone hypersecretion due to a primary pulmonary paraganglioma. Endocr Pract 2004;10:424-8. http://dx.doi.org/10.4158/EP.10.5.424

8. Otsuka F, Miyoshi T, Murakami K, et al. An extra-adrenal abdominal pheochromocytoma causing ectopic ACTH syndrome. Am J Hypertens 2005;18:1364-8. http://dx.doi.org/10.1016/i.amihyper.2005.01.019

9. Willenberg HS, Feldkamp J, Lehmann R, et al. A case of catecholamine and glucocorticoid excess syndrome due to a corticotropin-secreting paraganglioma. Ann N Y Acad Sci 2006;1073:52-8. http://dx.doi. org/10.1196/annals. 1353.006
10. Palau MA, Merino MJ, Quezado M. Corticotropin-producing pulmonary gangliocytic paraganglioma associated with Cushing's syndrome. Hum Pathol 2006;37:623-6. http://dx.doi.org/10.1016/i. humpath.2005.12.006

11. Flohr F, Geddert H. Images in clinical medicine. Ectopic Cushing's syndrome. N Engl J Med 201 1;365:e46. http://dx.doi.org/10.1056/NEJMicm1010540

12. Thomas T, Zender S, Terkamp C, et al. Hypercortisolemia due to ectopic adrenocorticotropic hormone secretion by a nasal paraganglioma: A case report and review of the literature. BMC Res Notes 2013;6:331. http://dx.doi.org/10.1186/1756-0500-6-331

13. Serra F, Duarte $S$, Abreu $S$, et al. Cushing's syndrome due to ectopic ACTH production by a nasal paraganglioma. Endocrinol Diabetes Metab Case Rep 2013:130038. http://dx.doi.org/10.1530/edm-13-0038

14. Erickson D, Kudva YC, Ebersold M J, et al. Benign paragangliomas: Clinical presentation and treatment outcomes in 236 patients. J Clin Endocrinol Metab 2001;86:5210-6. http://dx.doi.org/10.1210/ jcem.86.11.8034

15. Venkitaraman B, Karunanithi S, Kumar A, et al. 68Ga-Dotatoc Pet-Ct in the localization of source of ectopic ACTH in patients with ectopic ACTH-dependent Cushing's syndrome. Clin Imaging 2014;38:208-11. http://dx.doi.org/10.1016/i.dinimag.2013.10.007

16. Young WF Jr. Paragangliomas: Clinical oerview. Ann N Y Acad Sci 2006;1073:21-9. http://dx.doi. org/10.1196/annals.1353.002

17. Isidori AM, Kaltsas $G A$, Pozza $C$, et al. The ectopic adrenocorticotropin syndrome: Clinical features, diagnosis, management, and long-term followup. J Clin Endocrinol Metab 2006;91:371-7. http://dx.doi. org/10.1210/ic.2005-1542

Correspondence: Dr. Gang Yin, Department of Urology, Qilu Hospital, Shandong University, Jinan, Shandong, China; drgang_yin@126.com 